\title{
Our planet and us
}

\author{
Humans have altered their environment ever since they first appeared. Updates on three frameworks of \\ thinking about the scale of twenty-first-century human influence on the Earth are invigorating the global \\ change debate.
}

The mid-twentieth century may come to be known as the starting point of humanity's journey to the boundaries of sustainable stewardship. In an update ${ }^{1}$ of a 2004 synthesis report ${ }^{2}$, an analysis of 24 indicators of global change has revealed a 'Great Acceleration': a consistent steepening of trends since about 1950, towards higher levels of pollution, enhanced globalization and intensified use of Earth's resources.

The idea of the Great Acceleration ties in with two powerful conceptual frameworks that have been proposed over the last decade and a half to capture and illustrate the sheer scale of the human influence on planet Earth. One is the proposal of the Anthropocene ${ }^{3}$ as a potential new geologic epoch that marks the time when human activity expanded to the point that it made a global imprint in the geologic record. Another is the concept of 'Planetary Boundaries's, the suggestion that a 'safe operating space for humanity' can be delineated by drawing up limits to the extent of human activity that is sustainable, focusing on a handful of global-change issues around climate change, pollution and the use of land and water.

These story-lines have been discussed fervently, both in terms of their usefulness and in terms of whether the nitty-gritty quantifications at their foundation are actually possible. A definition of the starting point of the Anthropocene according to scientific criteria is still outstanding although one proposed start date ${ }^{5}$, the detonation of the first atomic bomb in 1945, nicely matches the kick-off identified for the Great Acceleration and left an anthropogenic signature in sediments worldwide.

A scientifically justified consensus of where exactly the safe limits might lie for each of the planetary boundaries, and what precisely the boundaries should be, is equally difficult to reach. An update to the concept ${ }^{6}$ now addresses some of these discussions, for example, by revising the quantifications of boundaries and adding new entities - such as human-made substances with the potential to alter the planet, such as chlorofluorocarbons - to the range of boundaries. Nevertheless, the precise values and details will remain

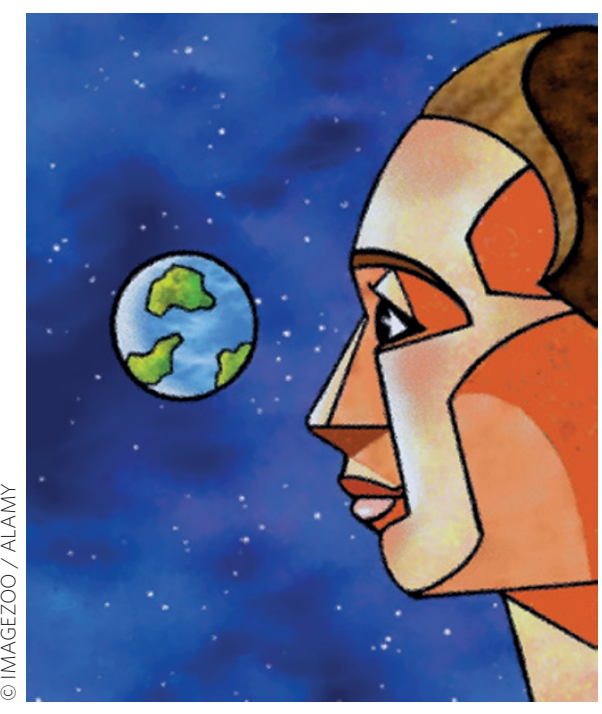

debatable and thus of questionable value for directly informing policy in a quantitative way. The story-lines of the Planetary Boundaries and of the Anthropocene work best as intuitively clear ways of thinking about global change that invigorate the public discourse - something they still $\mathrm{do}^{7}$. The Great Acceleration introduces a third strand that suggests a starting point for the Anthropocene and illustrates the current trajectory towards the Planetary Boundaries.

The assessment of the Great Acceleration ${ }^{1}$ emphasizes the close links between the economic system and the natural world. The first dozen indicators cover socioeconomic variables, such as the growth of population, primary energy use, urbanization and gross domestic product. The second dozen indicators are devoted to variables describing the Earth system concentrations of greenhouse gases such as carbon dioxide, methane and nitrous oxide, but also tropical forest loss and ocean acidification. An upward turn of the curve around 1950 can be identified in indicators across these two groups.

In a further step, new to the updated analysis ${ }^{1}$, the socio-economic indicators are stratified among the developed world (OECD countries), emerging economies (Brazil, Russia, India, China and South Africa) and the rest of the world. The exercise reveals strong but unsurprising equity issues - as we know, the largest rise in wealth (as measured by GDP) is not taking place in the parts of the world where population increases fastest. The analysis also resurrects the question of whether development for those at the lower end of the immense gap in living standards can be achieved by entering directly into a renewables-based low-carbon economy without first building an infrastructure that relies on fossil fuels. However, for China and India (and perhaps for other emerging economies), it may already be too late to leap-frog a fossil-fuel economy, considering existing commitments in infrastructure and carbon emissions trends ${ }^{8}$.

That the various conceptual frameworks are being updated and brought together at this point in time is unlikely to be mere chance. The initial proposal of the Planetary Boundaries concept fell into the hopeful yet heated run-up to the United Nations Framework Convention on Climate Change (UNFCCC) conference in Copenhagen in December 2009. This year, climate change negotiators are once again preparing their bids, this time for the December UNFCCC conference in Paris; the objective, committed to in Copenhagen, is nothing less than to achieve a legally binding global climate agreement. Of course, climate change is only one of the aspects of global change. But it is one of two critical, core boundaries ${ }^{6}$, climate and biosphere integrity.

It will take significant momentum and engagement of the public to fulfil the commitment for Paris. Powerful, intuitive story-lines are a key ingredient in achieving this engagement, even if they are largely illustrative.

\footnotetext{
References

1. Steffen, W., Broadgate, W., Deutsch, L., Gaffney, O. \& Ludwig, C. Anthrop. Rev. http://dx.doi.org/10.1177/2053019614564785 (2015)

2. Steffen, W. et al. (eds) Global Change and the Earth System: a Planet Under Pressure (Springer, 2004);

http://go.nature.com/ZqZeug

3. Crutzen, P. Nature 415, 23 (2002)

4. Rockström, J. et al. Nature 461, 472-475 (2009).

5. Zalasiewicz, J. et al. Quat. Int. http://dx.doi.org/10.1016/j. quaint.2014.11.045 (2015).

6. Steffen, W. et al. Science http://10.1126/science.1259855 (2015).

7. Revkin, A. C. Can humanity's 'Great Acceleration' be managed and, if so, how? Dot Earth (15 January 2015); http://go.nature.com/rNMgpn

8. Friedlingstein, P. et al. Nature Geosci. 7, 709-715 (2014).
} 